\title{
Entrevista com George Yúdice A cultura como recurso - desdobramentos dos Estudos Culturais
}

\author{
Interview with George Yúdice \\ Culture as a Resource - Developments from the Cultural Studies \\ Entrevista con George Yúdice \\ La cultura como un recurso - desarrollos desde los Estudios Culturales \\ MARISA VORRABER COSTA* \\ MARIA LÚCIA CASTAGNA WORTMANN** \\ $\diamond$
}

- Marisa: Temos imenso prazer em entrevistar o professor George Yúdice, da Universidade de Nova Iorque. ${ }^{1} \mathrm{O}$ professor Yúdice é nosso conhecido de longa data por seus inúmeros textos e entrevistas publicados, destacando-se, especialmente, os que examinam a cultura como um recurso e aqueles relacionados à noção de economia cultural, envolvendo preocupações com o retorno do capital cultural às comunidades locais, temas que aborda, particularmente, no livro intitulado A conveniência da cultura: usos da cultura na era global (editado no Brasil em 2004). Através deles, temos mantido contato com suas ideias e problematizações acerca da cultura contemporânea, todas muito fecundas para o desenvolvimento de nossos projetos de pesquisa e de nossos estudos neste campo novo - o dos Estudos Culturais. Esta entrevista é um privilégio, uma oportunidade que nos entusiasma muito e que, certamente, será muito produtiva para o prosseguimento de nossos estudos. Iniciamos, então, perguntando qual foi a sua reação ao receber o convite para fazer a abertura de um seminário cujo tema é Educação e Cultura Contemporânea.

$\square$ Yúdice: Bem, foi um convite que me fez pensar um pouco acerca de como as novas orientações a respeito da cultura incidem na educação. A conferência ${ }^{2}$ que preparei faz uma breve reflexão sobre esse tema. Estou muito agradecido porque gosto imensamente de vir ao Brasil, a Porto Alegre e agora a Canoas, que não conhecia ainda. Foi uma boa surpresa.

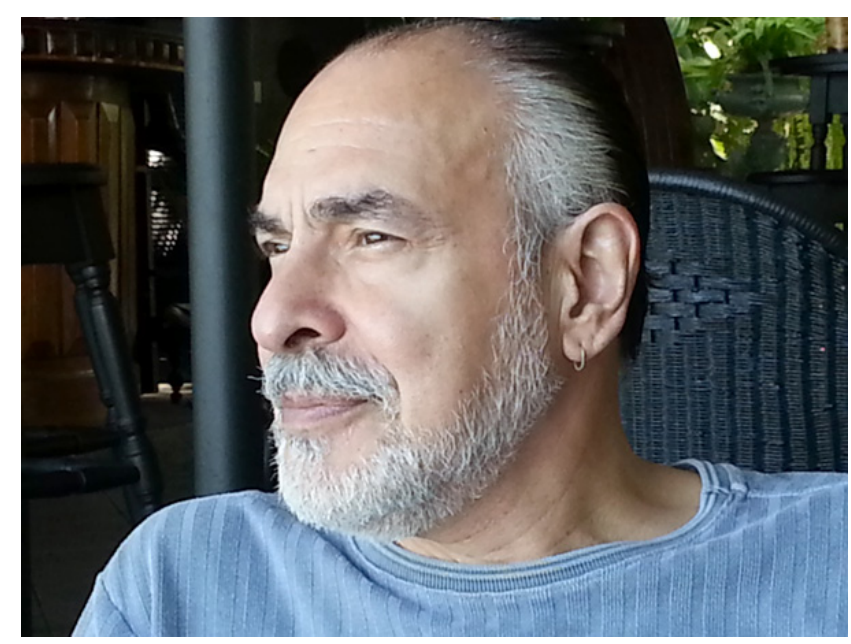

PROFESSOR GEORGE YÚdiCE

Fonte: Arquivo pessoal

Marisa: Para nós, sua presença também é importante. Além de tudo, é possível conversarmos nesse português bonito, quase sem sotaque, que nos faz esquecer tratar-se de um professor norte-americano e que vive nos Estados Unidos. Essa possibilidade de compartilhar a língua potencializa a comunicação e a troca de significados. Nossa intenção é abordar os vários focos para os quais seus trabalhos apontam, pois eles nos têm ajudado a pensar a educação sob outros ângulos, para além dos limites exclusivos da escola e da sala de aula, mas também dentro deles.

\footnotetext{
* Doutora em Ciências Humanas pela Universidade Federal do Rio Grande do Sul (Porto Alegre, RS, Brasil), professora na Universidade Luterana do Brasil (Canoas, RS, Brasil) e na Universidade Federal do Rio Grande do Sul (Porto Alegre, RS, Brasil). E-mail: < vorrabercosta@gmail.com>.

**Doutora em Ciências Humanas pela Universidade Federal do Rio Grande do Sul (Porto Alegre, RS, Brasil), professora na Universidade Luterana do Brasil (Canoas, RS, Brasil) e na Universidade Federal do Rio Grande do Sul (Porto Alegre, RS, Brasil). E-mail: <wortmann@terra.com.br>.
} 
- Maria Lúcia: Professor Yúdice, eu inicio lembrando um antigo texto seu, intitulado O "Estado das Artes" dos Estudos Culturais, publicado no ano de 1993, no Brasil, em um livro intitulado Comunicação e Cultura Contemporânea. ${ }^{3}$ Naquele texto, que foi o primeiro que eu li sobre Estudos Culturais, o senhor fez uma resenha das vertentes inglesas, estadunidenses e latino-americanas dos Estudos Culturais. Eu gostaria de saber, passados tantos anos, como o senhor vê o desenvolvimento dos Estudos Culturais nessas três realidades? E, ainda, a partir da proposta do Centro de Birmingham, que aspectos o senhor considera terem sido abordados mais distintivamente nessas vertentes?

$\square$ Yúdice: Bem, eu acho que no caso da Inglaterra e dos países da Commonwealth houve uma preocupação com as políticas culturais e a sua incorporação aos Estudos Culturais. Isso gerou uma tensão, pois os Estudos Culturais analisam as relações de poder que estão na sociedade e que perpassam a cultura. Aliás, a cultura é o lugar onde concorrem diversos grupos de interesse, e a política cultural tem um programa muito mais pragmático, voltado a mostrar como se organiza a cultura, como ela se financia etc. A novidade que ocorreu, quando eu estava escrevendo aquele texto, foi a virada do contexto inglês e a do australiano. Mais ou menos, nessa mesma época, alguns intelectuais latino-americanos também se preocuparam com a questão da política cultural, principalmente no México, onde Garcia Canclini e outros colegas começaram a refletir sobre o que seria aceitar o Acordo de Livre Comércio (ALCA) com os Estados Unidos. Tal acordo obrigou os professores e os intelectuais a pensarem nas várias repercussões que teriam a ver com questões legislativas, no que diz respeito à cultura. Nesse momento, portanto, eu acho que se iniciou o desenvolvimento desta nova orientação dos Estudos Culturais, não mais somente centrada na questão da hegemonia gramsciana, que era o prato forte dos Estudos Culturais britânicos, mas destinada a estudar outras questões. Nos Estados Unidos, os Estudos Culturais basicamente continuam desenvolvendo estratégias no que tange às relações das minorias: mulheres, minorias sexuais, homossexuais, lésbicas, etc. Hoje, tanto no contexto europeu quanto no latino-americano, está se ponderando sobre as políticas públicas no campo da cultura, como vemos, com muito mais força do que antes.

- Maria Lúcia: Então, nesse sentido, seu trabalho anda numa direção diferente desses estudos, porque, a partir da leitura de seu livro A conveniência da cultura: os usos da cultura na era global, ${ }^{4}$ algo que verdadeiramente me impressionou foi a amplitude e a diversidade de aspectos que o senhor aborda. Parece-me que seu trabalho lida com uma diversidade de movimentos sociais, transita pelas esferas institucionais e pelas organizações não governamentais (ONGs). O que me impressionou foram as muitas incursões que o senhor faz, nesse livro, a situações ocorridas em diferentes lugares, passando por Miami, nos Estados Unidos, Rio de Janeiro, no Brasil, Tijuana, no México. Enfim, parece-me que há uma peculiaridade no seu trabalho com relação a esses estudos.

- Marisa: Eu prossigo indagando nessa mesma direção. Tenho grande curiosidade em saber como se deu seu interesse pela cultura latino-americana. Isso porque penso que um dos aspectos que nos aproxima, que nos atrai em seu trabalho, é exatamente o fato de encontrarmos tantos pontos de contato entre os olhares que dirigimos à cultura brasileira e às questões da educação com o que você tem escrito acerca da cultura latino-americana. Eu gostaria de saber como se deu essa aproximação com os estudos latino-americanos e por que o interesse pelas questões da América Latina?

$\square$ Yúdice: Vou responder às duas perguntas. Nesse livro foram estudados vários casos que apresentam uma proposta teórica relacionada com o novo olhar a respeito da cultura. A cultura tem ligação com essa ideia de recurso. Ela se vale cada vez mais que isso, tanto para tentar resolver problemas sociopolíticos, por exemplo, de diversidade, de intolerância, quanto para ser um instrumento que impulsiona o crescimento econômico e a geração de emprego. Então, através desses casos, mostrou-se que essa preocupação não se limitava somente ao setor público, porque, na verdade, em todo o mundo, mesmo em países onde o Estado é muito forte, como na Europa, cada vez mais a empresa privada e o terceiro setor, o das ONGs e das fundações, estão se excedendo. A sociedade civil e os movimentos sociais tentam compreender como se está organizando e gerenciando a cultura. Esses setores devem ter uma ideia de como todas as forças públicas, privadas e o terceiro setor interagem. Depois disso, apresentei vários casos latino-americanos. Meu interesse pela cultura latino-americana é muito antigo. Começou com as letras, muitos anos atrás, nem vou dizer há quanto tempo. Os estudos das letras e das artes me levaram para os Estudos Culturais porque, em vários países da América Latina, as letras faziam parte de uma preocupação social. Muitos escritores tinham uma inquietude social, aliás, imensamente maior que nos Estados Unidos. Por exemplo, não se podia falar em literatura sem se falar em um escritor como Ferreira Gullar, que sempre esteve interessado nas questões sociais. Assim como ele, muitos outros também estavam e estão interessados numa arte engajada. Além disso, eu participava de um grupo, nos Estados Unidos, que 
estava começando a elaborar os Estudos Culturais, no final dos anos setenta. Portanto, eu fui a ponte entre esse grupo e vários intelectuais latino-americanos que analisavam a sociedade com esse novo olhar dos Estudos Culturais. Havia algumas perspectivas semelhantes, embora muitos deles nem tivessem lido sobre o grupo de Birmingham. Estou falando do final dos anos setenta e do começo dos oitenta, quando servi de elo, de interface para esses grupos. Porém, só no começo dos anos noventa consegui ter as condições institucionais necessárias para poder organizar encontros. Assim, por exemplo, Garcia Canclini e meu grupo organizaram um encontro sobre os Estudos Culturais no México, aonde chegaram muitas pessoas vindas do Brasil, da Argentina, da Venezuela, e de outras partes dos Estados Unidos. Com isso, acabei escrevendo um ensaio sobre as diferentes tendências desse encontro. Na época, nos Estados Unidos, eu notava uma preocupação, um grande interesse pelas questões de raça através da cultura. Já no Brasil e na América Latina isso ficava sempre em segundo plano. Evidentemente, hoje não! Outros assuntos, por exemplo os estudos sobre a sexualidade, já estavam bem elaborados nos Estados Unidos pelos Estudos Culturais, mas na América Latina eles ainda não aconteciam. Outra coisa que, na mesma época, ficou evidente na América Latina, era que também não se falava em performatividade, uma categoria importante nos Estados Unidos. Assim, havia algumas diferenças, mas muitas preocupações semelhantes. Interessei-me com intensidade, pois eu achava que os intelectuais latino-americanos que estavam trabalhando as questões culturais inovavam, produzindo ideias interessantes, numa perspectiva mais clássica, adorniana, como a Beatriz Sarlo, na Argentina, e mais "atualmente", a Heloisa Buarque de Holanda, no Rio de Janeiro, que parecia sempre estar na ponta, trabalhando com Nega Giza e outras questões. Havia várias pessoas importantes envolvidas com o debate pós-moderno na América Latina. Naquele momento, em particular, via-se como isso ocorria no Brasil, principalmente, através do encontro realizado no começo dos anos noventa.

- Marisa: De fato, alguns autores, principalmente os latino-americanos, tais como Garcia Canclini, têm se referido a isto: que o Brasil seria um país pósmoderno por excelência, devido às características plurais de sua cultura, às diferentes culturas étnicoraciais e religiosas que convivem entre si e a uma certa abertura dos brasileiros em geral, e da própria academia mesmo, em acolher toda essa diversidade, transformando tudo isso num "mix". Não estou querendo dizer que haja uma perfeita harmonia, mas sim, que parece existir alguma disposição para um acolhimento maior do que haveria em outras sociedades, quer seja na própria América Latina, quer seja em outros países estrangeiros. Você concorda com isso?

Yúdice: Eu acho que até pode ser, pois o que se elaborou nos anos sessenta, na Tropicália, é um exemplo de tendência cultural muito estudada, seja na vertente do Roberto Flats ou do Silviano Santiago. Embora tenham posicionamentos diferentes, os dois reconhecem que, naquele momento, se elaborou uma estrutura simbólica, como se ela fosse uma colagem, um colar de coisas diferentes, mas sem criar um amálgama dessas coisas. Elas mantinham suas diferenças e atribuíam essa novidade à Tropicália, tendência tanto de interesse pela cultura popular quanto pela cultura midiática. Quando se vê na música, por exemplo, novidades como o funk carioca, não com uma funkeira, mas com uma cantora de classe média e funkeira, a Fernanda Abreu, percebese como se manifesta a cultura de mixagem. Não estou falando de mistura no sentido mais tradicional, mas das tecnologias de mixagem, as que se produzem no estúdio. Por isso, eu acho que não é por acidente que, no Brasil, o funk e o rap são tão difundidos, é porque são músicas de mixagem. Muitos músicos dizem que a mixagem é uma maneira de ser brasileiro. Em certo sentido, outra palavra que se pode salientar é "sampler". A Fernanda Abreu tem uma música que diz "Be Sample", manifesto que afirma que ser brasileiro é ser "sampler". Eu imagino que isso já existia antes da época digital. Nesse sentido, estou de acordo que, de uma devida maneira, se recebem muitas influências. Na verdade, certos brasileiros não têm ansiedade nem com essa diversidade nem com a pureza. No Brasil, é difícil ser muito puro.

- Marisa: Outra característica que eu venho observando em minhas pesquisas, ultimamente, é um certo jeito brasileiro de viver, inclinado a não se preocupar mais ou muito com o futuro. Penso que compartilhamos uma cultura, com grandes diferenças e muitos matizes, mas voltada para o presente, ou seja, que procura extrair do presente tudo aquilo que ele pode oferecer de bom e de melhor. O que importa é ser feliz hoje, sem preocupar-se demasiadamente com o que vai acontecer amanhã. Isso porque, ao se pensar no amanhã, há muitas incertezas a respeito de ter dinheiro, comida e tantos outros itens importantes. $\mathrm{Eu}$ tenho percebido isso nas escolas frequentadas por crianças muito pobres. Elas chegam com roupas molhadas, porque choveu dentro do seu barraco, durante a noite, mas estão lá, na escola, vivendo com grande exaltação e alegria, sonhando que são cantoras de televisão ou top models, por exemplo. Bem, isso me parece algo que se aproxima desse etos pósmoderno da cultura brasileira, que antes comentamos. 
Yúdice: Mas isso seria uma mudança, porque pelo menos as elites tinham uma vontade moderna. Até Brasília, como uma cidade com plano piloto, é um salto para o futuro e, como dizíamos muito, que nunca chegava.

- Maria Lúcia: Em seu ponto de vista, a experiência do Viva Rio, relatada em seu livro, vale-se efetivamente, talvez, do desejo de a educação estar ocorrendo através de um engajamento aos movimentos musicais, como o funk, por exemplo. Você poderia falar um pouquinho mais sobre o projeto que comenta neste livro, ou seja, sobre essa forma de enxergar a educação, partindo da vinculação a esse tipo de movimento? E ainda, isso teria a ver com essa noção de performatividade que foi citada no seu texto? O quanto isso estaria se afastando da visão do intelectual transformador, que para nós foi extremamente presente, por exemplo, no trabalho de Paulo Freire e que encontra importante ressonância no trabalho de Daniel Mato? Aliás, percebemos certo estranhamento em Mato por não trabalharmos mais com o pensamento de Freire, consideração feita por ele mesmo em uma ocasião. Então, o senhor poderia explicar como essa visão performática se distancia da ideia de intelectual transformador que, para nós, do Brasil, e para outros países da América, foi tão fortemente apropriada, especialmente pelos educadores?

$\square \quad$ Yúdice: Neste momento, eu conversava a respeito disso com um amigo que está cursando um doutorado "sanduíche" em Nova Iorque e trabalhando com música. Ele é carioca e especializa-se em funk e rap. Estávamos falando que muitos grupos que estão atuando social, musical, cultural e, também, educativamente não precisam mais da intervenção do intelectual brasileiro. Eles mesmos são agentes. É o caso do José Júnior, coordenador do Afro Reggae, é o caso do Celso Ataíde, coordenador e diretor da CUFA - Central Única das Favelas -, de rapeiros como MV Bill, todos são intelectuais. Então, não é preciso que exista um Paulo Freire ou outra pessoa assim, mas isso também não quer dizer que eles não possam ter relações com intelectuais diferentes deles. Aqui o que está em jogo é a noção de que a agência mudou, não a ideia, mas a prática, a ideia de quem vai agenciar a transformação da sociedade. Será a iniciativa de um intelectual que irá animar a sociedade? Ou existem agentes sociais que estão achando maneiras de fazêlo? A maneira que eu descrevi aí, e que irei abordar mais tarde, é que essas figuras, esses grupos acharam uma maneira de praticar uma agência disseminada em redes, pois eles não trabalham sozinhos. O José Júnior, por exemplo, se empenhou, tal como o Ruben Cezar Fernandes, no Viva Rio, com jornalistas, com alguns funcionários do governo, com fundações, ONGs etc.
A iniciativa, e o que eles com ela conseguiram, aquilo que estão dizendo na atualidade, precisa ser avaliado como uma gestão complexa, pois eles descobriram de alguma maneira que não será uma pessoa que animará e mostrará como as outras pessoas poderão se emancipar, mas sim uma rede complexa que incidirá sobre todos, entre todos. Eu penso que existe uma grande relevância nesse agente, nesse ator, pois ele está difundindo cada vez mais a sua agência. Foi deste caso, e isso também é interessante, que eu falei no texto referido. Consciente ou inconscientemente, o educador sempre está mostrando e ensinando como se faz cultura, porém ele precisará ficar mais convicto do seu papel de gestor cultural. Não existe educação sem que esta esteja inserida na cultura, a educação já é uma maneira de gestionar (e de gerir) cultura, mas seria interessante mostrar aos alunos como se organiza o conceito de capacidade para agir. Agência, em outras palavras, é um anglicismo.

- Marisa: Eu observo que a televisão e as organizações empresariais estão se transformando em agências culturais muito poderosas. No Brasil, muitas empresas hoje financiam projetos culturais e educativos, como Petrobras, Fiat, bancos etc., e se percebe isso dentro das escolas. De repente, as circunstâncias que estão sendo vivenciadas nelas já são administradas e agenciadas por empresas. É um fenômeno novo em que organizações comerciais promovem a educação, mas também se aproveitam desse espaço catalisador e multiplicador que é a escola. Eu não sou totalmente contra isso, pois acho que existem algumas finalidades edificantes nesses projetos. Eles trazem algo que falta muito na educação formal pública brasileira, que são recursos financeiros. Contudo, o que me parece é que a educação vai escapando da escola, que era sua principal agência, tornando-se uma prática disseminada, assumida por muitos agentes com discutíveis interesses. Concordo plenamente que o professor precisa se dar conta de seu papel, para trabalhar com isso e para que as crianças consigam entender esses processos.

$\square$ Yúdice: A cultura incorporada na escola não poderá ser feita somente com os instrumentos do passado, porque ela já está funcionando de outra maneira, isto é, hoje ela está relacionada com a cultura empresarial, com a cultura do serviço social, com a cultura econômica. O professor tem de saber disso para se organizar melhor e para pensar no modo como os alunos irão compreender a noção de cultura e como irão atuar nela e sobre ela.

- Marisa: Do meu ponto de vista, o processo mais assustador e diante do qual o professor está menos preparado é o da entrada da mídia na vida escolar. 
De fato, é a colonização da vida das crianças e dos jovens pela mídia que repercute lá na escola de forma impressionante, mudando seu ritmo, seu jeito de ser, suas práticas, seu "formato". A ordem escolar está profundamente subvertida pelos fenômenos midiáticos, e as mídias atuais são extremamente competentes. Particularmente, no Brasil, a televisão, mas não somente ela, é extremamente competente em sua convocação.

$\square \quad$ Yúdice: Mas, onde mais os jovens passam o tempo? $\mathrm{Na}$ frente da televisão ou dos videogames. Para mim, esse parece um problema com que a escola não sabe lidar. O imaginário do jovem passa não só o imaginário, mas também as formas de interação com os outros, porque muitos videogames são interativos através da Internet, a ditar novas formas de relacionamento, principalmente com pessoas que eles não conhecem. Pode-se, por meio de um jogo de videogame, interagir com uma pessoa que está na Rússia. Portanto, o imaginário é uma forma de ação mútua entre as pessoas. $\mathrm{Na}$ realidade, o que falta é uma visão crítica da mídia, dos videogames, de tudo isso que está aí, porque eu entendo que os alunos precisam dessas e de outras formas culturais. Da mesma maneira, nós, que tivemos uma alfabetização voltada à cultura letrada, pelo menos nas boas escolas, precisamos passar por isso para depois fazermos uma crítica às letras e às mídias.

- Maria Lúcia: Essa era uma proposta que talvez estivesse contida nos estudos de Henry Giroux. Não sei se ele teve grande repercussão nos Estados Unidos, mas no Brasil os trabalhos de Giroux trouxeram uma contribuição importante em direção a uma leitura crítica das mídias. Aliás, parece-me que essa é uma ideia que tem circulado bastante entre nós, especialmente a partir da contribuição dos Estudos Culturais.

Marisa: Nos Estudos Culturais em educação praicados no Brasil, Henry Giroux, Shirley Steinberg, Joe Kincheloe e Douglas Kellner são os principais estudiosos norte-americanos inspiradores de pesquisas que tratam de mídia e cultura e se preocupam com questões educativas nelas implicadas. Entretanto, parece que na América Latina, os pesquisadores em Estudos Culturais começaram a tratar das relações entre cultura e mídia há um bom tempo. E aqui cabe uma ressalva. Quando falo em América Latina não estou me referindo ao Brasil, e justifico. Em julho de 2006, ao participar de um grande congresso internacional de Estudos Culturais - o Crossroads in Cultural Studies - um dos palestrantes que abordou os Estudos Culturais latino-americanos, após citar inúmeros nomes de pesquisadores de vários países da América do Sul e Central, em relação ao Brasil somente mencionou Renato Ortiz. Não se estendeu para além disso, parecendo-me estar implícita aí a ideia de que o Brasil é cada vez menos considerado como parte do que se denomina América Latina, sendo esta considerada como aquela dos países de língua espanhola. O Brasil, talvez por ser falante de língua portuguesa, sugere algo que o distinguiria das demais comunidades latino-americanas. Contudo, temos no Brasil já uma produção significativa filiada aos Estudos Culturais, sendo grande parte dela vinculada às aproximações entre os Estudos Culturais e a Educação. Temos utilizado o caractere @ para mostrar que essa relação é complexa e multifacetada - Estudos Culturais @ Educação. Por sua vez, os Estudos Culturais latino-americanos dedicam-se a outros tantos focos, sendo pouco destacada a produção voltada à educação. Penso que devido a isso ainda sejam poucos nossos interlocutores latino-americanos. Faço esse comentário porque gostaria de ouvi-lo acerca de sua percepção sobre o que estou mencionando.

Yúdice: Não conheço muito bem quem são os especialistas nos Estudos Culturais em Educação nos países hispano-americanos. [...] Também quero aproveitar para dizer uma coisa a respeito dos Estados Unidos. Lá existem pessoas que muito refletem sobre isso, porém, nos programas das escolas, em geral, elas não incidem, ficando tal reflexão limitada aos cursos universitários, às bibliografias, às livrarias. Nós não temos nem o ensino da arte, que acontece somente em escolas privadas e nos bons sistemas educativos locais. Na verdade, todos são locais nos Estados Unidos, só que para alguns o ensino das artes e da cultura não apresenta diferença entre estudar dança moderna, ópera e teatro. Logo, compreende-se que a noção de cultura que se tem hoje em dia está muito longe da que se estuda nas escolas. No entanto, eu creio que isso é muito importante, é tão importante quanto estudar o que lá se chama Estudos Cívicos, ou seja, a matéria que mostra como se organiza a sociedade, como ser um bom cidadão etc. Tudo é importante, principalmente, ter-se o estudo da cultura, sobretudo porque passamos e ainda estamos passando por guerras culturais nos Estados Unidos. Atualmente, a grande polaridade ocorre entre o fundamentalismo religioso e as pessoas mais liberais, citando, como exemplo, os homossexuais com seu matrimônio legalizado em vários estados. Nas escolas ensinam obrigatoriamente o criacionismo, e o criacionismo diz que a teoria da evolução é uma anticiência, mas que está sendo ensinada como ciência. Então, não há um estudo, na escola básica ou secundária, desse fenômeno chamado de cultura, apenas nas universidades. Isso empobrece muito a sociedade. 
- Marisa: Essa falta de repercussão nas escolas e nos cursos deve-se a políticas governamentais que, de certa forma, impedem isso?

$\square$ Yúdice: Bem, certamente, nesses casos muito conservadores onde se ensina o criacionismo, a repercussão não existe porque não se questiona o que é "natural" (e o "natural" seria o "normal"). Logo, questionaríamos [os praticantes de Estudos Culturais] o que é ser "normal". Mas, em geral, por outro lado, há um problema: isto é, não se fariam muitos questionamentos sobre o que é o "normal". Entendo que existe a crença de que na escola básica e secundária não se deve questionar o "normal". Essa questão é um grande problema dos estudantes: eles sempre estão se confrontando com o peso do normatismo. Sentem-se muito alienados, porque não são "normais" e não compreendem o que isso significa. Então, os Estudos Culturais seriam muito úteis, pois falam a respeito dessas questões.

- Marisa: Por que, então, os Estudos Culturais não são mais acolhidos na formação dos professores?

Maria Lúcia: Eu acho que essa desvinculação que se faz entre o meio universitário e a escola fundamental e média também acontece entre nós, não é? As discussões que se apresentam na universidade pouco se estendem para a rede escolar, porque tais situações mexem muito com as estruturas de poder que temos aí e não interessa tocar nisso. Há dois dias, eu li no jornal sobre um questionamento levado por uma criança da escola para sua casa. Esse surgiu quando ela estava estudando em seu livro escolar sobre o que era ser latifundiário. Bem, o avô dela era um latifundiário, e a pergunta da criança reproduzida no jornal era exatamente esta: "Ô mãe, o meu avô é um latifundiário?" Então, o que se discutia na reportagem era a impropriedade do que estava afirmado no livro didático, ou seja, criticava-se a focalização desta questão porque ela incidia sobre temas controvertidos, sensíveis, que melhor seria permanecerem camuflados.

Marisa: Enfim, nós poderíamos, talvez, retomar um pouco a conveniência da cultura e o assunto que nos tem ocupado atualmente. Ele tem tudo a ver com o eixo econômico, com o mercado, com o valor de troca das coisas e seu reflexo na sociedade contemporânea.

$\square$ Yúdice: Bem, a ideia do livro [A conveniência da cultura] é exatamente esta, a importância do consumo. Para mim, é preciso problematizar a posição que muitas pessoas ainda têm, a partir do trabalho de Theodor Adorno, de se colocarem contra as indústrias culturais. Isso não se justifica, exceto no sentido de que produziu mudanças em nossa natureza que, nos tempos atuais, é midiática de consumo, de cultura, etc. Portanto, teremos de pensar em como criar estratégias para fazer essa mudança de maneira democrática, crítica etc. Essa foi uma parte do que eu tratei no livro. De outra parte, temos outro ator, tão importante quanto o mercado, que é o setor das fundações, das ONGs e da cooperação internacional. Não sei se vocês estão cientes da extrema incidência da cooperação internacional francesa, espanhola, sueca, alemã, que existe na América Latina e, em geral, também no Brasil. O Afro Reggae foi financiado pelo comércio através da Fundação Ford. A Fundação Príncipe Klaus (da Holanda) financia isso e também outras ações culturais. A Organização dos Estados Ibero-Americanos (da Espanha) igualmente patrocina muitas atividades no Brasil. Portanto, esse é o outro setor, aquele que fala muito em direito e cidadania. A cultura que pensa em relação ao direito e à cidadania existe, em grande parte, pela ação desse setor. Dessa forma, temos dois usos: um que tem a ver com mercado, e outro que tem a ver com essas questões, que dizem respeito a fornecer aporte financeiro e mobilizar a cultura para resolver os problemas sociais. Exemplificando: se, em certa situação, há racismo ou intolerância, desenvolvem-se programas culturais para tentar resolver essa questão, isto é, para acabar com o desrespeito e a intolerância. Esses são os dois setores. Por isso, eu falo sempre sobre essa ideia de cultura virar recurso, ou melhor, que cultura é um recurso. Em nossa época, depois que se pensa assim, é que se começa a ver que a pessoa que "mexe" com cultura é um gestor. Assim como na natureza precisamos de gestores para que as populações não acabem com os recursos naturais, em relação à cultura também precisamos de gestores para administrá-la bem, favorecendo uma educação crítica. É interessante que surge agora uma figura que não existia há vinte anos, que é a do gestor cultural. Isso acontece, em parte, pelo mercado. Surge, nesse momento, a Petrobras como financiadora da cultura, aparecem também outras fontes, passa a vigorar a Lei de Incentivo à Cultura (LIC) etc. Tudo isso para se conseguir dinheiro. Também se precisa de gestores, mas parece haver, além disso, outra questão. O José Júnior, coordenador do Afro Reggae, é um gestor cultural muito inteligente. Ele diz que, para promover a sustentabilidade de seu projeto, ele precisa treinar seus gestores, senão o projeto acabará. A liderança não poderá ficar só com ele, tem-se que produzir mais gestores. A gestão é um fenômeno que antes era só do setor público, do governo, e, agora, dissemina-se nas sociedades latino-americanas em relação ao mercado e ao terceiro setor, ou seja, em relação à cultura. Isso é uma grande novidade, e tenho estudado esse assunto em vários casos. 
- Marisa: Tal questão corresponderia a esse ímpeto de governamentalidade de que fala Foucault, porque, de certa forma, quando esse gestor cultural está preocupado em formar mais gestores, é porque, com certeza, não quer que se perca a direção que está sendo impressa a determinados processos e movimentos culturais. Maria Lúcia: Nesse sentido, eu pergunto: a interlocução que alguns autores, como o senhor e o próprio Garcia Canclini, têm feito com as tendências de pensamento pós-estruturalistas e com os filósofos da pós-modernidade, de alguma maneira, parece que ampliam as possibilidades de discussão de como vinha sendo conduzida a cultura nos Estudos Culturais. No caso do Brasil, por exemplo, isso já causou uma cisão. Há uma autora ${ }^{5}$ que chega a pensar na existência de Estudos Culturais "mais adequados" e "menos adequados". Para ela, "os mais adequados" seriam exatamente aqueles que se aproximam da vertente de Birmingham e dos trabalhos de Raymond Williams, por exemplo. Os demais seriam os "menos adequados", menos puros, vamos dizer assim; ou seja, para ela, o que se afasta da vertente de Birmingham não é "essencialmente" Estudos Culturais. Novamente temos aquele entendimento de acharmos uma definição, um enquadramento dos Estudos Culturais, sendo essa, no entanto, uma perspectiva da qual seus praticantes têm que procurar fugir constantemente. Então, como fica a ideia da interlocução com as empresas?

- Yúdice: Claro, fui aprendendo muito estudando vários casos e descobri que o gestor é quem cria as relações, as retitulações para poder levar adiante um projeto, senão este morrerá. Não são modelos de ação, mas um modo de reflexão que vai além dos Estudos Culturais "puros", de Birmingham. Agora, é necessário agir em vários campos, muitas vezes, e trabalhar em outros com parcerias, etc. É mais complexo, mais flexível, e não se vê a ação somente através da reflexão teórica, mas isso envolve uma relação bem dinâmica entre reflexão e ação. Continuam sendo interessantes, por esse motivo, os trabalhos de Bourdieu e Stuart Hall. Eles têm uma perspectiva gramsciana. Stuart Hall elaborou também seus estudos a partir da perspectiva foucaultiana da governamentalidade. Essa visão foi a que mais se aproximou, em certo momento, desse processo que temos hoje, ou seja, da gerência da sociedade. Eu lembro, não sei se mencionei neste livro, acho que não, mas o primeiro que propôs o tema da governamentalidade nas políticas culturais, no contexto anglo-americano dos Estudos Culturais, foi Tony Bennet, que escreveu "O nascimento do museu". Essa obra alude à de Foucault intitulada $\mathrm{O}$ Nascimento da clínica.
- Marisa: Acho que essa oportunidade de podermos conversar sobre a importância dos Estudos Culturais com alguém que participou das primeiras discussões americanas sobre o campo foi ímpar. Esta conversa terá continuidade, certamente, porque é muito bom tomar contato com esse olhar de fora, evitando que fiquemos circunscritos às questões mais locais e internas. Temos também nossos "grilos" com a hegemonia anglo-saxônica dos Estudos Culturais, assim como temos vontade de que esse olhar latinoamericano e brasileiro, que se distingue dos demais Estudos Culturais, possa ter alguma visibilidade e contribuir para esse campo em desenvolvimento. Sabemos que os Cultural Studies constituem um campo controvertido, em permanente constituição e recomposição, afinado com políticas de abertura e de Crossroads. Sabemos que mesmo entre muitas tendências e disciplinas que possam apenas se cruzar contingencialmente, podemos compartilhar focos de convergência e fazer política. Muito obrigada, Professor.

Maria Lúcia: Finalizo lembrando comentário feito pelo Professor Denilson Lopes ${ }^{6}$, que destaca ser o Professor Yúdice um novo tipo de intelectual público capaz de realizar reflexões envolvidas, engajadas, amorosas, que implicam uma abertura metodológica, que não teme cair em um ecletismo teórico.

$\square \quad$ Yúdice: Agradeço muito.

\section{NOTAS}

1 Esta entrevista foi realizada em 2 de agosto de 2005 [...]. Naquela ocasião, o professor Yúdice era Professor da Universidade de Nova Iorque (USA). Atualmente, é professor de Línguas e Literatura Modernas e Estudos Latino-Americanos na Universidade de Miami (USA).

2 Conferência publicada em: SOMMER, Luís Henrique; BUJES, Maria Isabel Edelweiss (Org.). Educação e cultura contemporânea: articulações, provocações e transgressões em novas paisagens. Canoas: Ed. ULBRA, 2006.

3 In: PEREIRA, Carlos Alberto Messeder; FAUSTO NETTO, Antônio (Org.). Comunicação e Cultura Contemporâneas. Rio de Janeiro: Notrya, 1993.

4 YÚDICE, George. A conveniência da cultura: usos da cultura na era global. Belo Horizonte: Editora UFMG, 2004.

5 Trata-se de Maria Elisa Cevasco, que assim se manifesta em entrevista ao jornalista Maurício Santana Dias publicada na Folha de São Paulo de 25/05/2003. Disponível em: <http://www.boitempo.com/publicacoes imprensa.php? isbn=978-85-7559-014-0\&veiculo $=$ Folha $\% 20 \mathrm{de} \% 2 \overrightarrow{0}$ S.\%20Paulo>. Acesso em: 15 fev. 2013.

6 O Professor Denilson Lopes, na ocasião, atuava na Faculdade de Comunicação da Universidade de Brasília. Atualmente é professor da Escola de Comunicação da Universidade Federal do Rio de Janeiro. O comentário encontra-se na seção "Polêmicas" do Jornal Brasileiro de Ciências da Comunicação Ano 7, nº 268, São Bernardo do Campo, SP, Brasil, março de 2005.

Entrevista recebida em março 2014.

Aprovada em janeiro 2015 